\title{
FUNCTIONAL AND ADHERENCE ASSESSMENT IN CHILDREN AND ADOLESCENTS WITH THORACIC KYPHOSIS
}

\author{
Elena Amaricai ${ }^{1}$
}

\begin{abstract}
Thoracic kyphosis represents a widely spread spinal deviation that affects an increasing number of children and adolescents. It effects not only the development of children but can also have consequences on the ventilatory parameters and on the aerobic functional capacity. The objectives of our study were to assess the respiratory function and functional capacity in children and adolescents with thoracic kyphosis who followed a physical therapy program and to compare these parameters to healthy controls. Another objective was to evaluate the adherence of this category of patients to a supervised exercise program. 20 children and adolescents diagnosed with thoracic kyphosis and 20 gender and age-matched healthy controls were included in the study. Our patients performed a twelve-week supervised exercise program. They were assessed at the beginning and at the end of rehabilitation by spirometry (forced vital capacity-FVC, forced expiratory volume in 1 second-FEV1, peak expiratory flow-PEF and FEV1/FVC ratio) and functional capacity testing (6-minute walk test: 6MWT). A final assessment was conducted with the parents of the children and the adolescents with thoracic kyphosis where they completed an adherence questionnaire. In patients with thoracic kyphosis, their FVC, FEV1, PEF and 6-MWT scores improved significantly after the twelve-week program $(\mathrm{p}<0.0001)$. After rehabilitation there were no differences between the study patients and controls, except for the functional capacity which had lower values in children and adolescents with thoracic kyphosis. Adherence to an exercise-based program could improve the outcomes of the rehabilitation. Besides the respiratory function and functional capacity, assessing adherence to therapy and improving it should be considered when treating pediatric patients suffering from thoracic kyphosis.
\end{abstract}

UDC Classification: 616.08; DOI: http://dx.doi.org/10.12955/cbup.v6.1261

Keywords: Thoracic kyphosis, Exercise program, Respiratory function, Functional capacity, Adherence

\section{Introduction}

Thoracic kyphosis represents a widely spread spinal deviation that affects a high number of children and adolescents. The kyphosis can be related to poor posture or can be secondary to some diseases, the most frequent one being Scheuermann disease. Patients diagnosed with Scheuermann disease have an increased risk for back pain and a lower quality of the life than healthy patients (Ristolainen et al., 2012).

Exaggerated thoracic kyphosis effects not only the development of children but can also have consequences on their ventilatory parameters and aerobic functional capacity. The first-line treatment in pediatric patients with Scheuermann disease is conservative. It consists of rehabilitation and bracing (Bezalel et al., 2014; Pallazo et al., 2014; Bettany-Saltikov et al., 2017).

The objectives of our study were to assess the respiratory function and functional capacity of children and adolescents with thoracic kyphosis who followed a physical therapy program, and to compare these parameters to healthy controls. Another objective was to evaluate the adherence of this category of patients to a supervised exercise program.

\section{Methods}

The study included 20 children and adolescents with thoracic kyphosis, aged between 8 and 17 years old. 6 patients had Scheuermann disease, while the other 14 had postural thoracic kyphosis. 20 gender and age-matched healthy controls were recruited as controls.

The following demographic characteristics related to patients and controls were collected: age, gender, weight and height.

The study patients performed a twelve-week supervised exercise program in the outpatient Rehabilitation Department. The aims of the rehabilitation were: posture improvement, strengthening of the back, stretching the chest muscles, enhancing exercise capacity and increasing chest expansion.

The patients were assessed at the beginning and at the end of their rehabilitation period by spirometry (forced vital capacity-FVC, forced expiratory volume in 1 second-FEV1, peak expiratory flow-PEF and FEV1/FVC ratio) and functional capacity testing (6-minute walk test: 6MWT). The 6MWT was conducted according to a standardized protocol (ATS Committee, 2002). The subject was instructed to walk up and down a measured corridor, covering as much ground as possible over a 6-minute period.

\footnotetext{
${ }^{1}$ Department of Rehabilitation, Physical Medicine and Rheumatology, "Victor Babeș" University of Medicine and Pharmacy, Timișoara, Romania, ama.elena@gmail.com
} 
At final assessment parents of children and the adolescents with thoracic kyphosis was completed with an adherence questionnaire.

\section{Statistical analysis}

The statistical analysis was performed using the GraphPad Prism 5.0 program for Windows. Descriptive statistics were calculated for patients and controls characteristics, respiratory parameters and the 6-minute walk distance (mean and standard deviation).

\section{Results}

The study and control groups were homogenous in terms of their demographic features (Table 1).

\begin{tabular}{|l|l|l|l|}
\hline \multicolumn{2}{|l|}{ Table 1: Patients' and controls' baseline characteristics } \\
\hline Variables & Patients group & Control group & $p$ \\
\hline $\begin{array}{c}\text { Age (years) } \\
\text { mean } \pm \text { SD }\end{array}$ & $14.33 \pm 3.2$ & $14.33 \pm 3.2$ & Not significant \\
\hline $\begin{array}{c}\text { Height }(\mathrm{cm}) \\
\text { mean } \pm \mathrm{SD}\end{array}$ & $158.5 \pm 11.61$ & $159.7 \pm 7.21$ & Not significant \\
\hline $\begin{array}{c}\text { Weight }(\mathrm{kg}) \\
\text { mean } \pm \mathrm{SD}\end{array}$ & $47.6 \pm 12.08$ & $51.2 \pm 13.2$ & Not significant \\
\hline $\begin{array}{c}\text { Gender } \\
\text { Male- N (\%) } \\
\text { Female- N (\%) }\end{array}$ & $12(60 \%)$ & $12(60 \%)$ & Not significant \\
\hline Source: Author & $8(40 \%)$ & $8(40 \%)$ & \\
\hline
\end{tabular}

In patients with thoracic kyphosis, their FVC, FEV1, PEF and 6-MWT scores improved significantly after the twelve-week program. After rehabilitation there were no differences between the study patients and the controls, except for functional capacity which had lower values in children and adolescents with thoracic kyphosis (Table 2).

\begin{tabular}{|c|c|c|c|c|c|}
\hline & $\begin{array}{ll}\text { Patients } & \text { initial } \\
\text { evaluation } \\
(\text { mean } \pm S D)\end{array}$ & $\begin{array}{l}\text { Patients final } \\
\text { evaluation } \\
(\text { mean } \pm \text { SD) }\end{array}$ & $\begin{array}{l}p \\
\text { Patient initial } \\
\text { vs Final }\end{array}$ & $\begin{array}{l}\text { Controls } \\
\text { evaluation } \\
(\mathrm{mean} \pm \mathrm{SD})\end{array}$ & $\begin{array}{l}p \\
\text { Patient final } \\
\text { vs Control }\end{array}$ \\
\hline FVC (1) & $3.16 \pm 1.31$ & $3.36 \pm 1.34$ & $<0.0001$ & $3.65 \pm 1.33$ & 0.48 \\
\hline PEF (1/min) & $5.04 \pm 1.6$ & $5.17 \pm 1.64$ & $<0.0001$ & $5.34 \pm 1.67$ & 0.33 \\
\hline FEV1 (1/s) & $2.86 \pm 1.22$ & $2.99 \pm 1.21$ & $<0.0001$ & $3.18 \pm 1.15$ & 0.24 \\
\hline 6MWT (m) & $338.3 \pm 42.2$ & $351.2 \pm 40.2$ & $<0.0001$ & $382.7 \pm 40.7$ & 0.018 \\
\hline
\end{tabular}

All the parents of children with thoracic kyphosis agreed about the importance and the necessity of the physical therapy program for their children's health. On the other hand, only 8 of the 12 adolescents agreed with these facts; the other 4 disagreed or were indifferent.

\section{Discussion}

Thoracic kyphosis rehabilitation represents an important health program for children and adolescents. It is essential to diagnose it as early as possible and to start treatment. The treatment approach will be in most cases a conservative one, namely a tailored physical exercise program. Only the patients with severe structural kyphosis will be referred to surgery.

For the overall health status and function of the children, rehabilitation aims not only to improve their gait analysis and training (Suciu et al., 2016), but also to improve the proper development of their spine and develop better posture. The pain relief should not be underestimated as many patients present different levels of pain that can interfere with their everyday function and leisure activities, including participation in sport activities (Tanase et al., 2016).

Although we could not use different medical visualization systems in the course of the rehabilitation process (Virag et al., 2014), our pediatric patients had significant improvements of their ventilatory parameters and functional capacity after the physical exercise program. 


\section{Conclusion}

In children and adolescents with thoracic kyphosis, their respiratory parameters and functional capacity improved after a twelve-week supervised exercise program. When compared to controls, functional capacity had still lower values indicating the possible need for a further follow-up physical exercise program. Besides the respiratory function and functional capacity, assessing adherence to therapy and improving it should be considered when treating pediatric patients suffering from thoracic kyphosis.

\section{References}

ATS Committee on Proficiency Standards for Clinical Pulmonary Function Laboratories (2002). ATS Statement. Guidelines for the six-minute walk test. American Journal of Respiratory and Critical Care Medicine, 166: 111-117.

Bettany-Saltikov, J., Turnbull, D., Ng, S.Y., Webb, R. (2017). Management of Spinal Deformities and Evidence of Treatment Effectiveness. Open Orthop J, 11: 1521-1547.

Bezalel, T., Carmeli, E., Been, E., Kalichman, L. (2014). Scheuermann's disease: current diagnosis and treatment approach. J Back Musculoskelet Rehabil, 27(4): 383-390.

Palazzo, C., Sailhan, F., Revel, M. (2014). Scheuermann's disease: an update. Joint Bone Spine, 81(3): 209-214.

Ristolainen, L., Kettunen, J.A., Heliövaara, M., Kujala, U.M., Heinonen, A., Schlenzka, D. (2012). Untreated Scheuermann's disease: a 37-year follow-up study. Eur Spine J, 21(5): 819-824.

Suciu, O., Onofrei, R. R., Totorean, A. D., Suciu, S. C., Amaricai, E. C. (2016). Gait analysis and functional outcomes after twelve-week rehabilitation in patients with surgically treated ankle fractures. Gait Posture, 49: 184-189.

Tanasie, D., Catan, L., Popa, D., Hategan, S., Amaricai, E. (2016). Elaborate Ways for Approaching Autoimmune Rheumatoid Arthritis. Rev Chim, 67(5): 1023-1027.

Virag, I., Stoicu-Tivadar, L., Amăricăi, E. (2014). Browser-based medical visualization system. 9th IEEE International Symposium on Applied Computational Intelligence and Informatics, 355-359. 